\title{
刍议建筑企业税务风险及纳税筹划
}

\author{
周媛媛 \\ 武汉市汉阳市政建设集团有限公司 \\ DOI:10.32629/ej.v2i6.303
}

[摘 要] 建筑业是我国的基础产业,在我国经济发展的过程中发挥着非常重要的作用。随着实施营改增等政策以及经济体制改革的不断深入, 使建筑企业面临新的挑战,与此同时也为建筑企业带来了新的发展机遇, 在这种情况下,建筑企业应该对各种风险进行有效管控,使企业的综合竞 争力得到提高。在建筑企业所面临的风险中,税务风险比较严重,在全面推行营改增的背景下,建筑企业应该制定合理的策略,对各种税务风险进 行规避和管控,还应该积极促进纳税筹划工作的有效落实,使企业的税负压力得到降低,使企业利润得到提高。

[关键词] 建筑企业; 税务风险; 纳税筹划

建筑行业存在相对复杂的情况, 导致在营改增的背景下, 建筑企业收 入减少、税负增加等问题普遍存在, 特别是中小型建筑企业, 存在更加明显 的税务风险和财务风险, 同时由于不能有效的进行纳税筹划, 反而增加了 企业的税负。所以, 建筑企业应该对国家税收政策进行充分了解, 规避税务 风险并且科学有效的进行纳税筹划。

\section{1 建筑企业存在的税务风险}

1. 1增加税负的风险

在营改增实施前, 建筑企业只需要尽量的降低成本就可以获得更大的 利润。在营改增实施后, 建筑企业的计税方法以及税率等都发生变化, 如果 不能合理的进行纳税筹划, 会增加建筑企业应该缴纳的增值税, 进而增加 相关的附加税, 提高企业的税负。营改增后, 企业税负会在很大程度上受到 材料供应商类型的影响, 所以不能只对材料价格进行关注, 还应该从纳税 筹划方面进行考虑, 使企业能够在合理合法的基础上降低税负 ${ }^{[1]}$ 。

1.2 筹集资金的风险

很多时候建筑企业需要对工程进行跨区经营, 需要对增值税进行预缴, 增加了企业的资金需求。为了对市场规模进行扩展, 使企业长远发展的目 标能够得到实现, 建筑企业必须积极的对资金进行筹集, 在这个过程中会 伴随着各种筹资风险。我国相关的法律中规定, 建筑企业在异地提供建筑 服务产生的预收款以及收入都需要对相关的税款进行预缴。另外, 企业还 应该按照规定对相关的附加税进行缴纳 ${ }^{[2]}$ 。建筑企业工程的所需资金的数 量与资金筹集风险成正比, 并且企业还需要对部分资金进行垫付, 会影响 企业的资金运转。

1.3 合同风险

在获得工程项目后, 业主方会与建筑企业签订EPC合同, 很多企业的合 同内容不够全面和详细, 导致容易有问题在施工过程中出现, 进而导致各 种纠纷的发生, 使工程的工期得到延长。同时, 很多建筑企业不能规范的对 采购、施工、设计等环节的合同进行签订, 导致企业在纳税筹划时不能使 用对自身最有利的纳税方法, 进而提高企业税负 ${ }^{[3]}$ 。如果相关的工作人员 不能对税改后的相关政策进行正确认识, 没有对相关增值税的不同税率进 行合理利用, 那么会降低企业的收益。所以, 应该鼓励相关工作人员对最新 的税法知识进行了解和学习, 使这种风险能够得到有效避免。

\section{2 建筑企业规避税务风险和进行纳税筹划的策略}

2. 1 对材料供应商进行合理选择

在建筑企业的总成本中材料的成本占有很大的比重, 所以可以从具 体的材料采购工作入手进行税务筹划, 在营改增政策实施后, 供应商类 型不同建筑企业需要遵循的税率也不同。如果供应商在报价时包含税额, 建筑企业可以在一般纳税人处进行采购, 通过这种方式企业能够得到增
值税专用发票, 能够在一定程度上降低企业的税负。如果供应商之间存 在不同的报价, 建筑企业应该对净现金流量值等因素进行考虑, 保证企 业选择的供应商对企业纳税筹划最有利。如, 某建筑企业工程, 在仅考虑 采购建材的前提下, 存在 900 万元的含税工程款, 企业可以对甲、乙、丙 三家供应商进行选择。甲供应商为一般纳税人, 适用的税率为 $17 \%$, 可以 提供增值税专用发票, 给出 280.8 万元的含增值税报价。乙供应商是小规 模纳税人, 可以提供 $3 \%$ 税率的增值税专用发票, 给出 222.48 万元的含税 报价。丙供应商是小规模纳税人, 可以提供 $3 \%$ 税率的普通增值税发票, 并 且不能抵扣, 给出 219 万元的含税报价。建筑企业在对供应商的基本情况 进行了解后, 需要与自身的实际情况相结合, 利用净现金流量方法进行 纳税筹划。在供应商存在相同含税报价的前提下, 建筑企业应该选择存 在较高增值税税率的供应商, 从而能够取得增值税发票, 能够进行进项 抵扣, 能够使企业的抵扣税额得到增加, 使企业的税负压力得到减轻。经 过对甲、乙、丙三种采购方案进行计算, 当建筑企业选择甲供应商时可 以拥有 423.753 万元的现金净流量；当建筑企业选择乙供应商时可以拥 有 438. 6642万元的现金净流量; 当建筑企业选择丙供应商时可以拥有 435. 831 万元的现金净流量。所以, 选择乙经销商建筑企业能够实现企业 利益的最大化。

\subsection{EPC合同的纳税筹划}

建筑企业在对单一的EPC合同进行签订时需要拆分合同, 然后分别和 不同的业主进行合同的签订。在正常的情况下, 采购合同为 $13 \%$ 的税率, 施 工合同为 $9 \%$ 的税率, 设计合同为 $6 \%$ 的税率。以存在 720 万元含税总价款的工 程为例, 在EPC合同中存在 120 万元的设计价款、 270 万元的工程价款以及 330 万元的设备价款, 在不对合同进行拆分时, 该EPC合同适用 $13 \%$ 的税率, 所以, 应该缴纳 82.8318 万元的增值税额以及 12.5538 万元的附加税, 一共 需要 95.3856 万元的纳税总额。在合同进行拆分签订后, 材料和设备等费用 使用 $13 \%$ 的税率, 施工合同使用 $9 \%$ 的税率, 设计合同使用6\%税率, 经过核算 企业需要缴纳 77.0343 万元的纳税总额。通过进行分析比较, EPC合同在拆 分后, 能够使企业的税负得到有效降低。

建筑企业在对拆分EPC合同的纳税筹划方式进行利用的同时, 还应该 对合同的管理进行加强 ${ }^{[4]}$ 。在招投标前, 建筑企业应该详细的分析各类工 程项目, 在对工程项目进行选择时, 应该经过科学的计算预测项目的收益, 可以对无法满足收益需求的项目进行排除。在对外地工程项目进行选择时, 应该事先全面的对当地的招标方资质、诚信状况以及当地市场情况进行了 解, 使盲目投资的情况得到有效避免。另外, 企业应该对相关的保护性条款 进行明确, 为企业的利益提供有效保障。

2.3 对发票进行严格管理 


\title{
牛栏山酒厂市场营销策略研究
}

\author{
董泓延 \\ 首都经济贸易大学 \\ DOI:10.32629/ej.v2i6.288
}

[摘 要] 作为一个古老而特殊的行业,白酒行业的发展不断深入。要想以特色化维持长远发展, 赢得市场竞争力, 必须学会如何正确的面对和调 整自己。本研究探究了牛栏山酒厂的发展现状, 通过分析其营销策略的现状引出其营销策略中的问题,制定了相对的解决措施, 并在实际中能指 导其实际提高市场占有率、提升品牌地位。

[关键词]市场营销; 营销策略; 牛栏山酒厂

近年来, 以习近平为核心的党中央限制“三公消费”, 主张供给测改革, 消费对象的比例渐渐倾向于九零后, 他们渐渐倾向于白酒的消费, 以及电 商的快速发展导致白酒行业不得不面临转型, 白酒行业必须顺应时代发展, 深入探索营销措施, 制定创新性的发展措施。牛栏山酒厂作为白酒行业的 一员, 也面临着市场转型、市场萎缩的严峻考验, 让新的环境下的营销措施 更加完善, 提升该企业在白酒市场的核心竞争力, 是摆在牛栏山酒厂面前 急需解决的问题。

\section{1 牛栏山酒厂市场营销的现状}

牛栏山酒厂建于1952年, 当前的职工共有一千五百多人, 约占三百多 亩, 企业的重点生产对象是清新型的 “牛栏山” 四大系列, 共有两百多种。 这么多年以来, 传统的发酵工艺下, 完整保留了二锅头的清新、清爽、厚醇 以及纯净的特征。

1. 1 产品策略现状

近年来, 牛栏山加大了对产品品质的重视力度, 在保持白酒生产总量 不变的条件下, 将酒质由低档白酒向中档优质白酒转型。不仅如此, 还新增 万吨以上高品质基酒储存能力, 使得 “牛栏山” 的产品品质得以迅速提升。 与此同时, 酒厂在主导产品结构升级过程中也进行了许多调整, 形成了高 端黄瓷、中端三牛 (百年牛栏山陈酿)、低端牛栏山陈酿的产品结构。在“同 等价格比品质, 同等品质比价格”的前提下, 牛栏山酒厂的产品在市场上迅 速得到了消费者的认可。

1.2 价格策略现状

牛栏山的目标不仅是要做名酒, 还要做民酒, 受众更为普遍和广泛。在 做高端白酒时考虑到收入较高群体的心理定位与消费需求, 推出更高质量 的白酒, 同时又做牢经典玻璃瓶牛栏山的消费市场, 让普通老百姓也能喝 到健康的低价的名酒。在零售标价方面, 大都采取尾号为 “ 8 ” 的价格, 这 迎合了中国人对数字 8 的喜爱, 更是消费者对未来生活、工作的美好憧憬。
这种定价策略, 符合消费者喜欢讨彩头的心理, 受到消费的推崇与喜爱。此 外, 牛栏山用中高端酒进行品牌推广, 同时用低价格的酒来实现销量的突 破, 获得竞争优势。

\section{3渠道策略现状}

公司经过多年的精耕细作已经迈向 “泛全国化” 的市场道路, 在全国 区域内一级经销商数量 372 家、其中实现规模以上销售 (年销售额 1000 万以 上) 的经销商数量已达到 160 多家。众多经销商的参与、认可使普通大众广 泛认知、体验到 “牛栏山” 产品, 认可公司产品品质从而提升公司品牌影 响力。公司销售部目前只有 100 多名员工负责全国市场的市场营销工作, 精干的销售团队, 高素质人才队伍所创造的销售规模, 在全国白酒行业企 业中只有 “茅台” 酒厂能做到。

1. 4 促销策略现状

人员推销方面, 牛栏山当前属地招聘的业务人员将近 3000 人, 掌握着销 售网20余万家。营业推广方面, 牛栏山主要以陈列、地堆、端架为主。地堆 是其中最为常见的一种表现形式。

\section{2 牛栏山酒厂市场营销存在的问题}

2.1市场定位不清晰

按地理位置上分析, 以2018年为例, 2018年, 北京牛栏山实现营业利润 93.8 亿元, 北京市场实现营业利润 52.87 亿元。市外市场的营业收入为 40.21 亿元, 市内市场占有率较高, 然而其当前仍然过分倚重市内市场的增 长, 对于市外广阔的增量前景未做出战略性的投入定位。按产品价位上分 析, 低端产品与高端产品的销量共占总销量的 $70 \%$ 以, 而牛栏山现在依然 实行全价位产品一齐操作, 全价位操作使相关市场在投入及制定相关政策 时无法兼顾, 销售费用的投入无法聚焦, 造成费用的浪费以及不同系列产 品间的市场挤兄即产品内耗。

2.2 开发产品削弱了牛栏山整体品牌形象

在营改增的背景下, 建筑企业还应该对管理增值税发票的力度进行增 强, 使各种可能损害企业利益的情况得到有效避免, 使企业的税务风险得 到降低。首先, 建筑企业应该对管理发票的工作进行重视, 保证相关的工作 人员能够规范的开具、管理、获取发票。要将税额抵扣放在发票管理的重 要位置, 尽可能多获得增值税专用发票 ${ }^{[5]}$ 。同时, 企业应该对发票进行分类 管理, 与实际工作要求相结合对发票进行分类, 为检查和使用发票提供方 便。在实施营改增后, 增值税发票拥有越来越重要的作用, 企业的管理人员 需要对增值税发票的时效、种类等情况进行详细了解, 使企业管理发票的 水平能够得到提高。

\section{3 结束语}

综上所述, 建筑企业的管理者应该对防范税务风险的意识进行加强,

能够更加有效的管控和规避税务风险。同时, 建筑企业应该对纳税筹划的 工作进行重视, 尽量使企业的税务支出得到最大程度的降低, 使企业的利 润得到提高。

\section{[参考文献]}

[1]王培荣.当议如何有效控制商业地产税务筹划风险[J].商场现代 化,2019,890(05):169-170.

[2]曹益.浅谈施工企业的税务风险及防范[J].纳税,2019,13(04):44.

[3]黄欢.建筑企业税务筹划风险与对策研究 [J].纳税,2019,13(02):89.

[4]姜玉华. “营改增”后建筑施工单位纳税筹划分析[J].中国集体经 济,2019,602(18):104-105.

[5]王全胜.房地产企业税务风险管理探究[J].纳税,2019,13(08):3+6. 